RyAN, F. J. \& KIRITANI, K. (1959). J. gen. Microbiol. 20, 644-653

\title{
Effect of Temperature on Natural Mutation in Escherichia coli
}

\author{
BY F. J. RYAN* AND K. KIRITANI \\ Institute of Applied Microbiology, University of Tokyo, Japan
}

\begin{abstract}
SUMMARY: The mutation rate from histidine auxotrophy to prototrophy in Escherichia coli was measured during growth and in the stationary phase at different temperatures. During growth the rate of mutation/mutable unit $/ \mathrm{hr}$. had the same temperature coefficient as the rate of growth. Therefore the rate of mutation/ mutable unit/generation was the same at all temperatures. The temperature coefficient of the rate of mutation/unit/hr. during the stationary phase may be the same as that during growth, indicating that although mutation is slower in this phase it may involve the same process as during growth.
\end{abstract}

In Serratia marcescens the percentage of colour mutants in colonies of different size but of the same age has been shown to be equal (Kaplan, 1947). Similarly, it was shown by Novick \& Szilard that mutations of resistance to bacteriophage $\mathbf{T}_{5}$ may occur in Escherichia coli at a rate which is a function of absolute time and, within limits, not of the number of generations (Novick \& Szilard, 1950, 1953; see also Novick, 1956; Lee, 1953; Fox, 1955; Moser, 1958). The rate of mutation in both of these cases was further shown to have a $Q_{10}$ of c. 2. Because Novick \& Szilard used the chemostat which allowed the maintenance of identical growth rates at different temperatures, they were able to separate experimentally the effect of temperature on mutation from its effect on growth, a condition not met in previous studies on temperature and mutation. Unfortunately the chemostat device employed, which provides the desirable conditions of continuous logarithmic growth in a virtually constant environment, can be used simply for the measurement of few mutations, so far as is known; many mutants do not increase in the linear way predicted by theory, perhaps because of selection (Novick \& Szilard, 1950; de Rothschild, 1954; Moser, 1958). Consequently, the generality of Novick \& Szilard's conclusions on the properties of mutations in bacteria may be questioned.

Stocker (1949) found that the rate of mutation of factors influencing flagellar antigens and the growth of Salmonella typhimurium itself were influenced in the same way by temperature and nutritional conditions. Witkin (1953), using a completely different technique and resistance to bacteriophage $\mathbf{T}_{\mathbf{1}}$ in Escherichia coli showed that the temperature coefficients of spontaneous mutation/unit time and of cell division were identical; the $\boldsymbol{Q}_{10}$ again was $c$. 2. Thus, the natural mutation rate/generation was constant over

* Present address: Department of Zoology, Columbia University, New York 27, New York, U.S.A. 
a wide range of temperatures, causing different rates of growth. Furthermore, Fox (1955) and Moser (1958) showed that in the chemostat at rapid rates of growth (approaching those of unrestricted growth at $37^{\circ}$ ) the rate of mutation of $E$. coli to resistance to phage $T_{5}$ was a function of generation time.

The mutation from histidine auxotrophy $\left(\mathrm{h}^{-}\right)$to prototrophy $\left(\mathrm{h}^{+}\right)$in Escherichia coli offers several advantages in this connexion. It cannot be investigated in the chemostat, probably for reasons of selection resulting at least in part from the fact that new mutants do not increase in number until they have become homocaryotic through division (Ryan \& Wainwright, 1954; de Rothschild \& Ryan, 1953). The basis of this segregation delay resides in the fact that $h^{+}$is a dominant condition. Recessive mutations such as those to phage resistance, when studied by the method employed by Witkin, show a long delay in appearance. This interesting phenomenon is not completely understood (Witkin, 1956) but it is known that it is affected by temperature. On the other hand, a dominant prototrophic mutant, such as $\mathrm{h}^{+}$, must express its character on minimal medium before it can divide. The $\mathrm{h}^{-} \rightarrow \mathrm{h}^{+}$mutation can be measured among bacteria which are in a stationary phase where they do not divide (Ryan, 1955). Thus the responses of growth, of multiplication and of mutation to temperature can be separated. The present paper reports the effect of temperature on mutation $\mathrm{h}^{-} \rightarrow \mathrm{h}^{+}$during growth and in the stationary phase.

\section{METHODS}

The basic techniques used were the usual ones employed in our investigations of mutation from the histidineless $\left(\mathrm{h}^{-}\right)$to the histidine independent $\left(\mathrm{h}^{+}\right)$ condition in strain 15 of Escherichia coli (Ryan, 1955). Medium supplemented with enough histidine to support the growth of $c .10^{7} \mathrm{~h}^{-}$organisms/ml., was distributed in $2 \mathrm{ml}$. volumes into large numbers of small test tubes, and were freshly inoculated to contain $c .25$ washed $\mathrm{h}^{-}$bacteria $/ \mathrm{ml}$. The cultures were placed in incubators maintaining the specified temperatures to within $1^{\circ}$.

Viable counts were made at intervals by plating appropriate dilutions from a sample of these tubes on minimal agar supplemented with $25 \mu \mathrm{g}$. L-histidine $\mathrm{HCl} / \mathrm{ml}$. and incubating at $37^{\circ}$. In this way the rate of growth, the total yield of bacteria and the rate of death during the stationary phase was determined. Until the stationary phase had set in, the number of viable bacteria was indistinguishable from the total number measured in a counting chamber. Thereafter, although the total number remained constant for weeks, the viable number decreased according to the function

$$
N_{t}=N_{0} e^{-k t},
$$

where $N_{t}$ is the number of viable bacteria at time $t, N_{0}$ the number at time $O$ and $k$ a constant. During growth, mutations from $\mathrm{h}^{-}$to $\mathrm{h}^{+}$occurred in some of the tubes. The $\mathrm{h}^{+}$mutants are not limited by the exhaustion of histidine but overgrow the cultures in which they are found until they use up the glucose present which allows the growth of about $5 \times 10^{8}$ bacteria $/ \mathrm{ml}$. Thus, 
cultures with adaptive $h^{+}$overgrowths were turbid and those without $h^{+}$ mutants appeared clear to the naked eye. Among groups of 100 tubes reserved for this purpose, the frequency of tubes without mutants $\left(\boldsymbol{P}_{\mathbf{0}}\right)$ can be determined. By using the zero term of the Poisson formulation

$$
\boldsymbol{P}_{0}=e^{-m},
$$

$m$, the average number of mutations, can be calculated. This can be inserted, along with $N$, the average number of bacteria/tube at the end of growth, into the equation which defines the mutation rate:

$$
a=\frac{m \ln 2}{N},
$$

where $a$ is the chance of mutation/bacterium/generation.

The $\mathrm{h}^{+}$adaptive overgrowths did not cease to appear at the time expected when the $h^{+}$mutants arose during growth; rather new adaptations occurred for weeks after the onset of the stationary phase. In order to determine the length of the interval required for the overgrowth by $\mathrm{h}^{+}$mutants which arose at the very end of growth, single $\mathrm{h}^{+}$mutants marked with an inability to ferment lactose were added at that time (average addition $0.5 \mathrm{~h}^{+}$lac $^{-}$ bacteria/culture; therefore, $\mathbf{3 0} \%$ of the cultures should have received one, $8 \%$ two, and $1 \%$ three bacteria). When the cultures had adapted they were streaked on lactose eosin methylene-blue agar to determine whether the adaptation was due to an added lac- bacterium. Since lac ${ }^{-}$and $\mathrm{lac}^{+}$bacteria grow on glucose at equal rates the average times for overgrowth were determined at the different temperatures. These times, as well as those required for the $h^{-}$bacteria to reach the stationary phase, are shown in Table 1 . The sum of these times is that after which the tubes were observed in order to estimate the frequency of mutations arising during growth.

Adaptations which occurred after this time were counted for the measurement of mutations occurring during the stationary phase (Ryan, 1955). The rate/bacterium/hr. $(\mu$.) was calculated by the formula

$$
\mu .=\frac{k m}{N_{0}\left(1-e^{-k t}\right)},
$$

where $k$ is taken from equation (1), $m$ is calculated according to equation (2) for adaptations occurring after the total times in Table $1, t$ is the length of the interval in hours (hr.) over which observations were made and $N_{0}$ is the number of bacteria present at the beginning of the interval minus the number of hours required for adaptive overgrowth at the various temperatures. It has already been shown that these adaptations in the stationary phase are the result of mutations which occur during that period in non-dividing organisms (Ryan, 1955).

\section{RESULTS}

Table 2 shows the way in which the rate of growth and the rate of mutation during growth varied with temperature. Over the range of temperatures from 20 to $30^{\circ}$ the rates of mutation calculated/organism/generation were indis- 
tinguishable. Because generations require longer times as the temperature decreases, the rate of mutation/hr. decreased with temperature.

The measurements at $15^{\circ}$ require special consideration. It is possible that for technical reasons the total number of organisms present was not accurately estimated. But even when the number of organisms actually present is taken as $1.7 \times 10^{7}$ (the average of experiments at other temperatures), the calculated

\begin{tabular}{|c|c|c|c|}
\hline Temp. & $\begin{array}{l}\text { Time to } \\
\text { the stationary } \\
\text { phase in } \\
\text { limiting } \\
\text { histidine } \\
\text { (hr.) }\end{array}$ & $\begin{array}{c}\text { Time for } \\
\text { overgrowth } \\
\text { of single } h^{+} \\
\text {lac-bacteria } \\
\text { (hr.) }\end{array}$ & $\begin{array}{c}\text { Time at } \\
\text { which mutants } \\
\text { arising during } \\
\text { growth should } \\
\text { be observed } \\
\text { as adaptive } \\
\text { overgrowths } \\
\text { (hr.) }\end{array}$ \\
\hline $15^{\circ}$ & 132 & 160 & 292 \\
\hline $20^{\circ}$ & 64 & 83 & 147 \\
\hline $25^{\circ}$ & 44 & 48 & 92 \\
\hline $30^{\circ}$ & 34 & 35 & 69 \\
\hline $87^{\circ}$ & 22 & 27 & 49 \\
\hline
\end{tabular}

Table 2. The rates of growth and of mutation during growth at different temperatures

\begin{tabular}{|c|c|c|c|c|c|c|c|c|}
\hline Temp. & $\begin{array}{l}\text { No. of } \\
\text { experi- } \\
\text { ments }\end{array}$ & $\begin{array}{c}\text { Genera- } \\
\text { tion } \\
\text { time } \\
\text { (hr.) }\end{array}$ & $\begin{array}{c}\text { Average } \\
\text { no. of } \\
\text { viable } \\
\text { bacteria/ } \\
\text { culture } \\
\left(\times 10^{-7}\right)\end{array}$ & $\begin{array}{l}\text { Average } \\
\text { no. of } \\
\text { mutations/ } \\
\text { culture }\end{array}$ & $\begin{array}{l}\text { Mutation } \\
\text { rate/ } \\
\text { bacterium } / \\
\text { genera- } \\
\text { tion } \\
\left(\times 10^{-8}\right)\end{array}$ & $\begin{array}{c}\text { Range } \\
\left(\times 10^{-8}\right)\end{array}$ & $\begin{array}{c}\text { Mutation } \\
\text { rate/ } \\
\text { bacterium/ } \\
\text { hr. } \\
\left(\times 10^{-8}\right)\end{array}$ & $\begin{array}{c}\text { Range } \\
\left(\times 10^{-8}\right)\end{array}$ \\
\hline $15^{\circ}$ & 7 & $4 \cdot 9$ & $1 \cdot 1$ & $1 \cdot 14$ & $\begin{array}{c}7 \cdot 0 \\
(3 \cdot 5)^{*}\end{array}$ & $5 \cdot 1-9 \cdot 3$ & $\begin{array}{c}1 \cdot 4 \\
(0 \cdot 7)^{*}\end{array}$ & $1 \cdot 0-1 \cdot 9$ \\
\hline $20^{\circ}$ & 5 & 2.5 & 1.6 & 0.67 & $\mathbf{3 \cdot 0}$ & $2 \cdot 5-3 \cdot 5$ & $1 \cdot 2$ & $1 \cdot 0-1 \cdot 4$ \\
\hline $25^{\circ}$ & 6 & $1 \cdot 7$ & 1.8 & 0.71 & $2 \cdot 9$ & $2 \cdot 0-3 \cdot 8$ & $1 \cdot 7$ & $1 \cdot 2-2 \cdot 3$ \\
\hline $30^{\circ}$ & 7 & 1.3 & $1 \cdot 6$ & 0.59 & $2 \cdot 9$ & $1 \cdot 9-5 \cdot 3$ & $2 \cdot 2$ & $1 \cdot 5-4 \cdot 1$ \\
\hline $37^{\circ}$ & 5 & 0.92 & 1.8 & 0.83 & $3 \cdot 2$ & $2 \cdot 7-3 \cdot 6$ & $3 \cdot 5$ & $3 \cdot 0-3 \cdot 9$ \\
\hline
\end{tabular}

rate of mutation is still significantly higher because of the absolutely greater average number of mutations/culture. It was thought that at this temperature the average number of mutable units/organism might be larger, although the rate of mutation/mutable unit/generation might be the same as at other temperatures. Previous work at $37^{\circ}$ had shown that the number of mutable units was c. 4 (Ryan \& Wainwright, 1954; Ryan, Fried \& Schwartz, 1954). Serial transfer experiments at $15^{\circ}$ were therefore performed to measure the rate of increase of the $h^{+}$mutants. The mutation rate calculated from the slope of the increase curve should be equal to the rate calculated by the Poisson method if there is one mutable unit/organism, reduced to $1 / 2$ if there are 2 mutable units, to $1 / 4$ if there are four, and so on. In the serial transfer 
experiments the proportion of $\mathrm{h}^{+}$mutants increased exponentially rather than linearly according to the relation

$$
\frac{\mathrm{h}^{+}}{\mathrm{h}^{-}}=\frac{g a}{n}
$$

where $g$ is the number of generations, $a$ the rate of mutation/organism/generation and $n$ the average number of mutable units/organism. The exponential results obtained indicated that there was a selection for the $h^{+}$bacteria at $15^{\circ}$, a phenomenon not observed at $37^{\circ}$. The initial slope of the increase curve was, however, c. $9 \times 10^{-9}$ which when compared with the value of $7 \times 10^{-8}$ found in the Poisson experiments, suggested the presence of 8 instead of 4 mutable units as had been found at $37^{\circ}$ by the same scheme of comparison (Ryan \& Wainwright, 1954). Therefore, when the mutation rates at other temperatures were divided by 4 and that at $15^{\circ}$ by 8 , indistinguishable mutation rates/ mutable unit/generation are obtained.

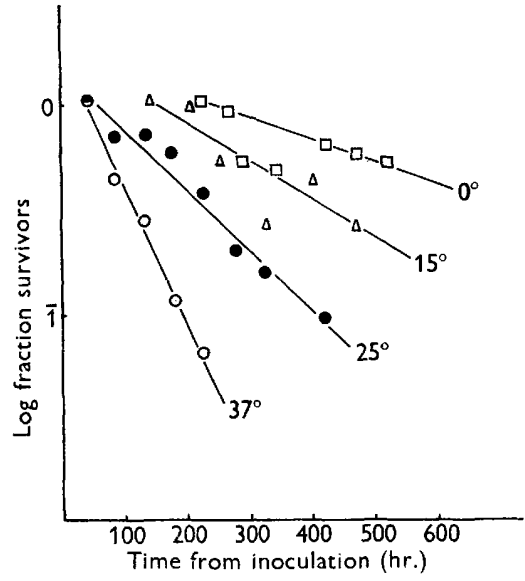

Fig. 1

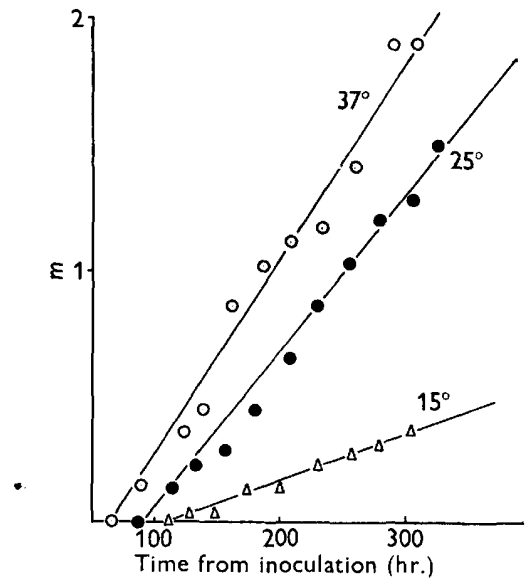

Fig. 2

Fig. 1. Examples of decrease in viability during the stationary phase at different temperatures. The rate constants from equation (1) were: for $0^{\circ}, 2 \cdot 5 \times 10^{-8}$; for $15^{\circ}, 4.2 \times 10^{-3}$; for $25^{\circ}, 6.4 \times 10^{-3}$; for $37^{\circ}, 1.5 \times 10^{-2}$.

Fig. 2. Examples of increase in the average number of mutations/culture, $\mu$, during the stationary phase at different temperatures. Equation (2) was used to calculate $m$; $P_{0}$ was set at 1.00 after the mutants arising during growth had been accounted for at the times indicated in Table 1 . The abscissa for the curve for $15^{\circ}$ has been shortened by $180 \mathrm{hr}$. for convenience. The data at $15^{\circ}$ yielded a mutation rate, $\mu$, of $0.17 \times 10^{-9}$; those at $25^{\circ}$ a rate of $0.71 \times 10^{-9}$; and those at $37^{\circ}$ a rate of $1.6 \times 10^{-9}$.

Table 3 and Figs. 1 and 2 show the relation to temperature of the rate of death and of the rate of mutation/hr. in the stationary phase. At $0^{\circ}$ no growth occurred so that death at that temperature was determined with cultures grown at $37^{\circ}$ and then transferred to $0^{\circ}$, while mutation was investigated by transferring back again to $37^{\circ}$. Although more than $40 \%$ of the organisms were still surviving at the time of the last transfer, no mutations could be detected in addition to those which had occurred during the initial growth 
at $37^{\circ}$ and those which occurred continuously upon return to $37^{\circ}$ at a rate characteristic of that temperature $\left(1 \cdot 0 \times 10^{-9}\right)$. The data in Table 3 are the average of three experiments at each temperature; the time periods studied averaged $239 \mathrm{hr}$. and covered $167-434 \mathrm{hr}$.

Table 3. Summary of the average rates of death and of mutation in the stationary phase at different temperatures

\begin{tabular}{|c|c|c|c|c|}
\hline Temp. & $\begin{array}{l}\text { Constant for } \\
\text { the rate of } \\
\text { death } \\
\left(\times 10^{-3}\right)\end{array}$ & $\begin{array}{c}\text { Range } \\
\left(\times 10^{-3}\right)\end{array}$ & $\begin{array}{c}\text { Rate of } \\
\text { mutation/ } \\
\text { bacterium/ } \\
\text { hr. } \\
\left(\times 10^{-9}\right)\end{array}$ & $\begin{array}{c}\text { Range } \\
\left(\times 10^{-9}\right)\end{array}$ \\
\hline $0^{\circ}$ & $4 \cdot 6$ & $2 \cdot 5-6 \cdot 7$ & $<0.0006$ & - \\
\hline $15^{\circ}$ & $6 \cdot 3$ & $4 \cdot 2-10 \cdot 0$ & 0.12 & $0.07-0.17$ \\
\hline $20^{\circ}$ & $6 \cdot 8$ & $4 \cdot 8-9 \cdot 4$ & 0.24 & $0 \cdot 14-0.30$ \\
\hline $25^{\circ}$ & $7 \cdot 8$ & $5 \cdot 0-12 \cdot 0$ & $1 \cdot 2$ & $0.71-1.4$ \\
\hline $30^{\circ}$ & 9.5 & $6 \cdot 1-13 \cdot 4$ & $1 \cdot 1$ & $0 \cdot 69-1 \cdot 3$ \\
\hline $37^{\circ}$ & $14 \cdot 2$ & $7 \cdot 7-18 \cdot 0$ & $1 \cdot 4$ & $0 \cdot 96-1.9$ \\
\hline
\end{tabular}

Figure 3 shows graphically the relation to temperature of the rates of mutation during growth and during the stationary phase and, as well, of the rate of growth and the rate of temperature-sensitive death during the stationary phase. The latter statistic was calculated by subtracting the $k$ value at $0^{\circ}$ from the $k$ value determined according to equation (1) for any temperature. Because of the scatter of the data it is not certain whether the relation is curvilinear, such as is frequently found for biological events, or whether there is a constant temperature coefficient such as a $Q_{10}$ lying between 2 and 3 . In any event it is not possible to reject the hypothesis that all four events have the same temperature relation.

The number of nuclei (Feulgen-positive bodies)/organism was determined during growth and in the early and late stationary phase at different temperatures. The organisms were fixed in osmic acid vapour, hydrolysed in $\mathrm{HCl}$ and stained with Giemsa by the usual techniques. The nuclei were usually easy to count in all organisms in contrast to the preparations reported previously (Ryan \& Wainwright, 1954). The average number of nuclei was 1.8 with an insignificant variation from $1 \cdot 5$ to $2 \cdot 1$, irrespective of stage or temperature.

\section{DISCUSSION}

The results of these investigations on the effect of temperature on the natural rate of mutation/bacterium/hr. are in accord with the findings of Witkin (1953). This rate and the rate of growth have the same temperature relation; therefore, the rate of mutation/generation is the same at all temperatures. For this reason it might be suspected that mutations are caused by something that happens a given number of times/generation; e.g. mutations might be the result of errors in the replication of the genetic material. On the other hand, these findings are not necessarily, nor are those of Witkin, in disagreement with the report of Novick \& Szilard (1950) that bacterial mutations occur at 


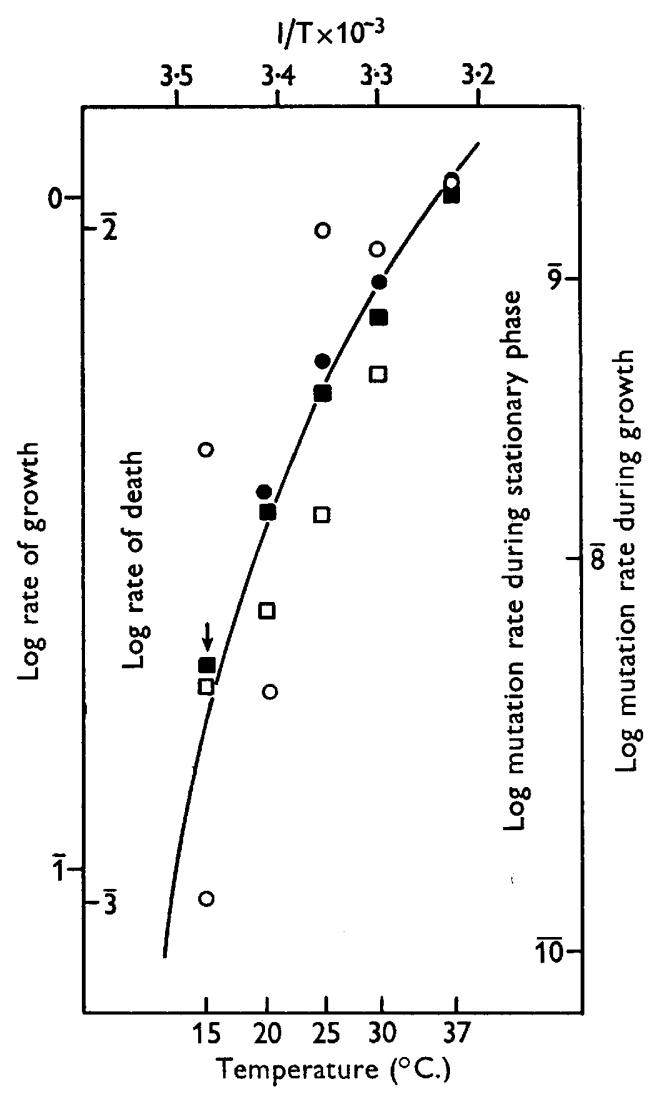

Fig. 3. The relation to temperature of the logarithms of the rates of mutation during growth (closed circles), of mutation during the stationary phase (open circles), of growth itself (closed squares), and of death during the stationary phase (open squares). The mutation rates are in terms of the chance of mutation $/$ bacterium $/ \mathrm{hr}$; the growth rates are expressed as $\ln 2$ divided by the generation time; and the death rates are the $k$ values, calculated according to equation (1), from which the $k$ at $0^{\circ}$ was subtracted in order to compare just the temperature sensitive death with the rate of mutation. The curve was drawn by eye. If the value for mutation rate during growth at $15^{\circ}$ is divided in half to correct for the presence of twice as many mutable units as usual, it falls to the point indicated by the arrow. The abscissa above measures the reciprocal of absolute temperature while that below is not exactly linear, because the reciprocal of absolute temperature is only approximately an inverse linear function of temperature in degrees Centigrade over this range (Belehradek, 1935).

rates which are independent of the length of generation time, the exceptions being very fast rates such as those which occur during unrestricted growth at $37^{\circ}$ (Fox, 1955; Moser, 1958) and very slow rates where the generation time may be longer than $15 \mathrm{hr}$. and the organisms are frequently in the lag phase (Lee, 1953). It is conceivable that at each temperature the $\mathrm{h}^{+}$ mutations occurred as a function of time, not growth rate; different rates of growth at a single temperature were not studied in the present case nor by Witkin, as was done in the experiments of Novick \& Szilard. It would then be 
necessary to assume that the temperature coefficients of mutation and growth are identical either by coincidence or even because mutation is some function of division. As Novick (1956) pointed out, if mutations occurred at a constant rate/time unit during some critical period of division and if the length of this period were a constant proportion of the length of a generation, they would still be time-dependent. This might be the case if, for example, natural mutations were the result of DNA replication while adenine was in the rare tautomeric state or if they were a function of some metabolism that depended upon temperature but was independent of the limitations in nutrition used to change the rate of growth within the chemostat. But it is still a question whether in the present case and in that of Witkin there is a fixed chance of mutation/division at all temperatures or whether at a given temperature this chance is a function of the length of the generation time.

This problem has not been solved and the issue is further confused by technical difficulties. For example, it is necessary to compare mutation rates on a per mutable unit basis. If bacteria in the chemostats operating at different flow rates contain different numbers of mutable units, as nuclei or nuclear subunits, then the comparisons on a per bacterium basis would be confounded. By special methods the number of mutable units $/ \mathrm{h}^{-}$bacterium has been measured, but no direct attempts have been made to do the same with bacteria in the chemostat growing at different rates and mutating to phage resistance. Although indirect estimates may be made, they are uncertain and in conflict (cf. Fox, 1955; Novick, 1956, Fig. 5).

If mutations only occur during replication and mutation is a copy-error (Fabergé \& Beale, 1941; Newcombe, 1953), then the fact that mutations occur in non-dividing bacteria requires an explanation. The metabolic activity of $\mathrm{h}^{-}$bacteria in a histidine-limited stationary phase where there is no division is indicated by a rapid consumption of glucose (Ryan \& Schneider, 1949). Thus there seems to be the possibility of a continued synthesis of genetic material, perhaps in the course of a metabolic turnover. This could conceivably be an unbalanced synthesis that leads eventually to death. Such a supposition is consistent with the probability that the rate of death and the rate of mutation in the stationary phase have the same $Q_{10}$ as is indicated in Fig. 3. But unfortunately the lack of precision, and consequent difficulty in estimating the significance of small differences, does not allow the rejection of the interpretation that between $25^{\circ}$ and $37^{\circ}$ mutation in the stationary phase is essentially temperature independent.

It seems that little can presently be learned, as was once hoped (TimofeefRessovsky, Zimmer \& Delbrück, 1935) from an analysis of the temperature relation of mutation via the Arrhenius equation

$$
k=A e^{-W / R T},
$$

where $k$ is some measure of rate, $A$ a frequency factor, $W$ the activation energy, $\boldsymbol{R}$ the gas constant and $\boldsymbol{T}$ absolute temperature. The activation energy, $W$, if constant over the temperatures studied, may be of the order of $\mathbf{0 . 5} \mathrm{eV}$. Since it is not even known as yet whether natural mutations are 
monomolecular or bimolecular or both, the significance of the frequency factor $A$ is doubtful. As was the case with the mutation to phage $\mathrm{T}_{5}$ resistance studied by Novick \& Szilard (1950), a reversion from one homocysteineless condition in Ustilago maydis (Ishikawa \& Tanaka, 1957) and mutation to the homocysteineless condition in an unstable strain of the same organism (Ishikawa, 1957), the $\boldsymbol{A}$ for mutation during growth is extraordinarily small. As a matter of fact, not only $W$ but also $A\left(5 \times 10^{-4} / \mathrm{sec}\right.$. $)$ is almost the same for mutation to $\mathrm{h}^{+}$during growth as for mutation to $\mathrm{T}_{5}$ resistance $\left(A=10^{-3}\right)$. In view of numerous uncertainties (Glasstone, Laidler \& Eyring, 1941; Hinshelwood, 1951; see also the negative temperature characteristics of Fabergé \& Beale, 1941 and Rhoades, 1941), the fact that the frequency factor $A$ is small, or that it varies with conditions and is $2 \times 10^{-2} / \mathrm{sec}$. for mutation to $\mathrm{h}^{+}$during the stationary phase, cannot assure us that mutation is or is not a monomolecular process nor that the activated state is of long duration.

The exact study of mutation demands a greater precision in measurement than is now available. Although Lederberg (1955) suggested that spontaneous mutations can be measured with a precision of 5-10\% with continuous flow devices such as the chemostat, a survey of the published data reveals discrepancies exceeding $30 \%$ in mutation rates which should be identical. Rates determined by other methods may have a higher precision (Ryan, Schwartz \& Fried, 1955). Further, the thermodynamic analysis of mutation requires more extensive experimentation (McElroy \& Swanson, 1951) and needs be supplemented by other approaches.

One of us (F.J.R.) was the recipient of a Fulbright Fellowship during the year $1955-1956$.

\section{REFERENCES}

Belehradek, J. (1935). Temperature and Living Matter. Berlin: Gebrüder Borntraeger.

DE Rothschild, B. (1954). Mutant equilibrium in the chemostat. Proc. 9th Int. Congr. Genetics, pt. II, 977.

DE RothschitD, B. \& RYAN, F. J. (1953). Selective differences between new and old bacterial mutants. Proc. 6th Int. Congr. Microbiol. 1, 726.

Fabergé, A. C. \& Beale, G. H. (1941). An unstable gene in Portulaca: mutation rate at different temperatures. J. Genet. 43, 173.

Fox, M. S. (1955). Mutation rates of bacteria in steady state populations. J. gen. Physiol. 39, 267.

Glasstone, S., Laidier, K. J. \& Eyring, H. (1941). The Theory of Rate Processes. New York: McGraw-Hill.

Hinshelwood, C. N. (1951). The Structure of Physical Chemistry. Oxford: Clarendon Press.

IsHIKAWA, T. (1957). An unstable strain of Ustilago maydis. Jap. J. Genet. 32, 213.

IshikaWa, T. \& TANAKA, N. (1957). Effects of temperature on reversion rate of homocysteineless mutants of Ustilago maydis. Bot. Mag. Tokyo, 70, 183.

KaPlan, R. W. (1947). Spontane Mutabilität bei Bacterium prodigiosum. Z. Naturf. $2 b, 308$. 
Lederberg, J. (1955). Genetics and microbiology. In Perspectives and Horizons in Microbiology, pp. 24-39, by Waksman, S. A. New Brunswick: Rutgers University.

LEE, H. H. (1953). The mutation of $E$. coli to resistant bacteriophage $T_{6}$. Arch. Biochem. Biophys. 47, 438 .

McElroy, W. D. \& Swanson, C. P. (1951). The theory of rate processes and gene mutation. Quart. Rev. Biol. 26, 348.

Moser, H. (1958). The dynamics of bacterial populations maintained in the chemostat. Publ. Carneg. Instn, no. 614, 1-136.

Newcombe, H. B. (1953). The delayed appearance of radiation-induced genetic change in bacteria. Genetics, 38, 134.

Novick, A. (1956). Mutagens and antimutagens. Brookhaven Symp. Biol. 8, 201.

Novick, A. \& SzILARD, L. (1950). Experiments with the chemostat on spontaneous mutations of bacteria. Proc. nat. Acad. Sci., Wash. 36, 708.

Novick, A. \& SzILARD, L. (1953). Experiments on spontaneous and chemically induced mutations of bacteria growing in the chemostat. Cold Spr. Harb. Symp. quant. Biol. 16, 337.

Rhoades, M. M. (1941). Genetic control of mutability in maize. Cold Spr. Harb. Symp. quant. Biol. 9, 138.

RYAN, F. J. (1955). Spontaneous mutation in non-dividing bacteria. Genetics, 40, 726.

Ryan, F. J., Fried, P. \& Schwartz, M. (1954). Nuclear segregation and the growth of clones of bacterial mutants induced by ultraviolet light. J. gen. Microbiol. 11, 380.

Ryan, F. J. \& Schneider, L. K. (1949). The consequences of mutation during the growth of biochemical mutants of Escherichia coli. IV. The mechanism of inhibition of histidine-independent by histidineless bacteria. J. Bact. 58, 201.

Ryan, F. J., Schwartz, M. \& Fried, P. (1955). The direct enumeration of spontaneous and induced mutations in bacteria. J. Bact. 69, 552.

RYAN, F. J. \& WAINwright, L. K. (1954). Nuclear segregation and the growth of clones of spontaneous mutants of bacteria. J. gen. Microbiol. 11, 364.

Stocker, B. A. D. (1949). Measurements of rate of mutation of flagellar antigenic phase in Salmonella typhimurium. J. Hyg., Camb. 47, 398.

Timofeef-Ressovsky, N. W., Zimmer, K. G. \& Delbrück, M. (1935). Über die Natur der Genmutation und der Genstruktur. Nachr. Ges. Wiss. Göttingen, Fachgruppe, 6, N.F. 1, 189.

WrTkIN, E. M. (1953). Effects of temperature on spontaneous mutations in Escherichia coli. Proc. nat. Acad. Sci., Wash. 39, $42 \%$.

Witkrn, E. M. (1956). Time, temperature and protein synthesis; a study of ultraviolet-induced mutations in bacteria. Cold Spr. Harb. Symp. quant. Biol. 21, 123.

(Received 1 December 1958) 